\title{
Optimization of processing parameters for making alumina-partially stabilized zirconia laminated composites
}

\author{
S DEB* and B V RADHAKRISHNA BHAT \\ Defence Metallurgical Research Laboratory, Kanchanbagh, Hyderabad 500 058, India
}

MS received 9 August 1999; revised 21 January 2000

\begin{abstract}
The aim of the work was to optimize the processing parameters for fabricating laminated ceramic composites of $\mathrm{Al}_{2} \mathrm{O}_{3}-\mathrm{Y}-\mathrm{PSZ}$. Composites of different layer thicknesses, starting from $2 \mathrm{~mm}$ and going down up to $0.3 \mathrm{~mm}$, were made by hot-pressing. The different types of cracks originating in the composite were studied in detail and the reason behind their formation analysed. The observed main reasons for crack formation were: (i) differential shrinkage in between the co-sintering layers due to their different sintering kinetics, (ii) thermal expansion mismatch, and (iii) a tensile component of the residual stress in the layer under residual compressive stress. After this defect analysis, suitable remedial measures were taken to avoid the crack formation. And finally a laminated composite with fifteen layers of $0.3 \mathrm{~mm}$ thickness was made successfully.
\end{abstract}

Keywords. $\quad \mathrm{Al}_{2} \mathrm{O}_{3}-\mathrm{Y}-\mathrm{PSZ}$ laminated composites; hot pressing; residual stress; transverse cracks; longitudinal cracks.

\section{Introduction}

Laminated ceramic composites have been an area of extensive research in recent years. This is because of the reason that they offer an improvement in various properties over their monolithic counterparts. Laminated composites are fabricated by stacking layers with specific compositions in a predetermined sequence to achieve improved physical or mechanical properties. The main advantage of these composites is the tailorability of their composition to meet the desired property requirements. The properties of the individual layers are usually tailored by controlling the composition and microstructure. The only limitation in choosing the constituents is the compatibility of their thermal expansion coefficient, thermal stability and processibility. The basic reasons behind the improvement in the strength, toughness and reliability of these composites are the crack diverting characteristics of the inter-lamina interfaces and the second phase particles, whiskers or fibres in the lamina. Macrostructural modifications like introducing surface or bulk compressive stress are also used to improve their properties (Amateau et al 1993). The principal effect of laminating the composite layers is the introduction of interfaces into the body which are weak enough to deflect propagating cracks, yet strong enough to give useful compressive and shear properties. Ceramic composites have been produced in a simple and economic fashion by bonding composite elements sepa-

*Author for correspondence rated by some weak interface (Clegg et al 1990). Silicon carbide sheets coated with graphite have been used to make this type of composite. In this material catastrophic failure of silicon carbide was prevented and the apparent fracture toughness was raised from 3.6 to $17.7 \mathrm{MPa} \sqrt{\mathrm{m}}$ and the work of fracture from 28 to $6152 \mathrm{~J} / \mathrm{m}^{2}$, which is comparable to that of wood (Clegg 1992). There are a number of possible routes for fabrication of laminated composites like powder processing, tape casting, centrifugal slip casting, co-extrusion, electrophoretic deposition etc. Out of the various processing methods, the powder processing route offers the most convenient way of making laminated composites of simple shapes. Hence this route was followed for making the composites.

\section{Experimental}

The $\mathrm{ZrO}_{2}-\mathrm{Al}_{2} \mathrm{O}_{3}$ system was chosen for making the initial exploratory trials. Commercially available 3 mole\%-yttria partially stabilized zirconia (PSZ) and alumina powders were used as the raw materials. A few rectangular bar shaped samples were tried via the cold die pressing and subsequent sintering route. But it was found that the samples were getting curved and cracked extensively during the sintering process due to the stress generated because of the thermal expansion mismatch. To avoid this cracking it was decided to go for vacuum hot pressing route. Since in this route it is possible to maintain a restraining pressure on the sample to prevent curving during the cooling stage when the thermal residual stress is generated. The component powders were stacked inside a 
powder compaction die in the form of thin layers of designated thickness. Various layer thicknesses of the individual laminates were targeted. Disc shaped samples of $75 \mathrm{~mm}$ dia were vacuum hot pressed at a pressure of $27 \mathrm{MPa}$ within a temperature range of $1500^{\circ}-1550^{\circ} \mathrm{C}$ for $1 \mathrm{~h}$. Cooling rate was controlled to be within $3^{\circ}-5^{\circ} \mathrm{C} / \mathrm{min}$. Table 1 gives the structure and composition of different samples produced and the sample designations. For comparison of the properties of the laminated composite with that of the individual constituents, two disc shaped compacts were made by hot-pressing PSZ and alumina powders separately. Both the powders were hot pressed at $1525^{\circ} \mathrm{C}$ for $1 \mathrm{~h}$ at a pressure of $27 \mathrm{MPa}$. For determination of thermal expansion coefficients of the two materials, small rectangular bars of $4 \times 4 \times 25 \mathrm{~mm}$ were cut from these hot pressed discs. The thermal expansion coefficient measurement was done by using a Netzsch DIL $402 \mathrm{C}$ machine within a temperature range of $20^{\circ}$

The experimental values of CTE are $12.123 \times 10^{-6} /{ }^{\circ} \mathrm{C}$ for PSZ and $9.0206 \times 10^{-6} /{ }^{\circ} \mathrm{C}$ for alumina.

\section{Results and discussion}

Before the results can be discussed, it is essential to know the nature of the residual stresses generated during the processing.

\subsection{Residual stress}

The residual strain developed in a ceramic laminate consisting of thin layers of two different materials, 1 and 2, due to their thermal expansion mismatch is given by

$$
\varepsilon_{\mathrm{r}}=\int_{T_{\mathrm{i}}}^{T_{\mathrm{f}}}\left(\alpha_{1}-\alpha_{2}\right) \mathrm{d} T,
$$

where $T_{\mathrm{i}}$ and $T_{\mathrm{f}}$ are the initial and final temperatures during cooling, and $\alpha_{1}$ and $\alpha_{2}$ are the thermal expansion coefficients (CTE) of the two materials 1 and 2, respectively. After cooling to room temperature from the processing temperature, the layer with the higher CTE value comes under bi-axial residual tensile stress and the layer with the lower CTE value comes under a bi-axial compressive stress. At points far away from the free surface, inside the layer, this residual stress is uniform and bi-axial in both the layers. There is no residual stress in the direction of stacking at these points. The compressive residual stress $\left(\sigma_{R 1}\right)$ in the layer with the lower CTE value is given by (Oeschner et al 1996)

$$
\sigma_{\mathrm{R} 1}=\frac{\varepsilon_{\mathrm{r}} E_{1}^{\prime}}{1+\frac{t_{1} E_{1}^{\prime}}{t_{2} E_{2}^{\prime}}}
$$

Here $t_{1}$ and $t_{2}$ are the layer thicknesses of the respective material and $E^{\prime}=E /(1-v)$, where $E$ and $v$ are Young's modulus and Poisson's ratio, respectively. The bi-axial tensile stress $\left(\sigma_{\mathrm{R} 2}\right)$ in the higher CTE layer is given by

$$
n_{2} \sigma_{\mathrm{R} 2}=-n_{1} \sigma_{\mathrm{R} 1} \frac{t_{1}}{t_{2}}
$$

where $n_{1}$ and $n_{2}$ are the number of layers of materials 1 and 2 respectively in the composite.

Apart from these bi-axial stresses, the existence of another residual tensile stress can be explained with the help of figure 1 . The two interfaces as well as the bulk of the alumina layer is under bi-axial compressive stress $\sigma_{\mathrm{R}}$, acting in the direction of $x$-axis. Considering a small volume element $\mathrm{d} V$ on the free surface on the right hand side, there will be a tensile stress $\sigma_{\text {yy }}$ acting in a direction perpendicular to the compressive stress, along the direction $y$. This tensile stress will help in generating cracks or in opening up any pre-existing flaws in a direction parallel to the interface as shown in figure 1. Though bi-axial compressive stress exists in the layer far away from the free surface, the stress distribution near the free surface is triaxial (Ho et al 1995). The component of the tri-axial stress acting perpendicular to the centreline of the layer $\sigma_{y y}$ is a highly localized tensile stress, which diminishes rapidly in magnitude with distance from the surface to the interior. The magnitude of this tensile stress, $\sigma_{\mathrm{yy}}$, at a distance $x$ from the free surface, along the centreline of the layer is given by (Ho et al 1995)

$$
\sigma_{\mathrm{yy}}(x) l_{\mathrm{y}=0}=\frac{2}{\pi}\left[\theta-\frac{1}{2} \sin 2 \theta\right] \sigma_{\mathrm{R}},
$$

where

$\tan \theta=t / 2 x$,

Table 1. Structure and composition of the different samples and the sample designations.

\begin{tabular}{lccl}
\hline Sample designation & No. of layers & Layer thickness & \multicolumn{1}{c}{ Composition } \\
\hline AZ2 & 05 & $2 \mathrm{~mm}$ & Alternate layers of $\mathrm{Al}_{2} \mathrm{O}_{3}$ and Y-PSZ \\
$\mathrm{AZ1}$ & 05 & $1 \mathrm{~mm}$ & Alternate layers of $\mathrm{Al}_{2} \mathrm{O}_{3}$ and Y-PSZ \\
$\mathrm{AZ03}$ & 09 & $0.3 \mathrm{~mm}$ & Alternate layers of $\mathrm{Al}_{2} \mathrm{O}_{3}$ and Y-PSZ \\
$\mathrm{AZ1503}$ & 15 & $0.3 \mathrm{~mm}$ & Alternate layers of $\left(\mathrm{Al}_{2} \mathrm{O}_{3}+15\right.$ vol.\% Y-PSZ) and \\
& & (Y-PSZ + 15 vol.\% $\left.\mathrm{Al}_{2} \mathrm{O}_{3}\right)$ \\
\hline
\end{tabular}


and $\sigma_{\mathrm{R}}$ is the absolute value of the residual bi-axial compressive stress inside the layer, far away from the free surface. The above (4) and (5) indicate that the stress distribution along the centreline is highly dependent on the thickness, $t$, of the layer under compression and also on the magnitude of the residual stress $\sigma_{R}$. A strain energy release rate function for a crack in this localized tensile stress field, developed by Ho et al (1995) is as follows:

$$
G=\frac{0 \cdot 34 \sigma_{\mathrm{R}}^{2}\left(1-v^{2}\right)}{E} t .
$$

The critical layer thickness below which these cracks also known as 'edge-effect cracks' do not occur is thus given by

$$
t_{\mathrm{c}}=\frac{G_{\mathrm{c}} E}{0 \cdot 34\left(1-\mathrm{v}^{2}\right) \sigma_{\mathrm{R}}^{2}},
$$

where $G_{\mathrm{c}}, E$ and $v$ are the critical strain energy release rate, Young's modulus and Poisson's ratio of the layer material, respectively. The value of this critical layer thickness, $t_{\mathrm{c}}$, was calculated from (7). It was found to be $0.2 \mathrm{~mm}$, which implies that there should not be any edgeeffect cracking in alumina layers thinner than $0.2 \mathrm{~mm}$.

\subsection{Processing defects}

The initial sample was targeted with an individual layer thickness of $2 \mathrm{~mm}$ and contained five alternate layers of alumina and PSZ of same thickness with alumina at the two surfaces. This sample (AZ2) came out with extensive cracking throughout. The cracks were both transverse and in-plane in nature. The two main reasons for crack genera-

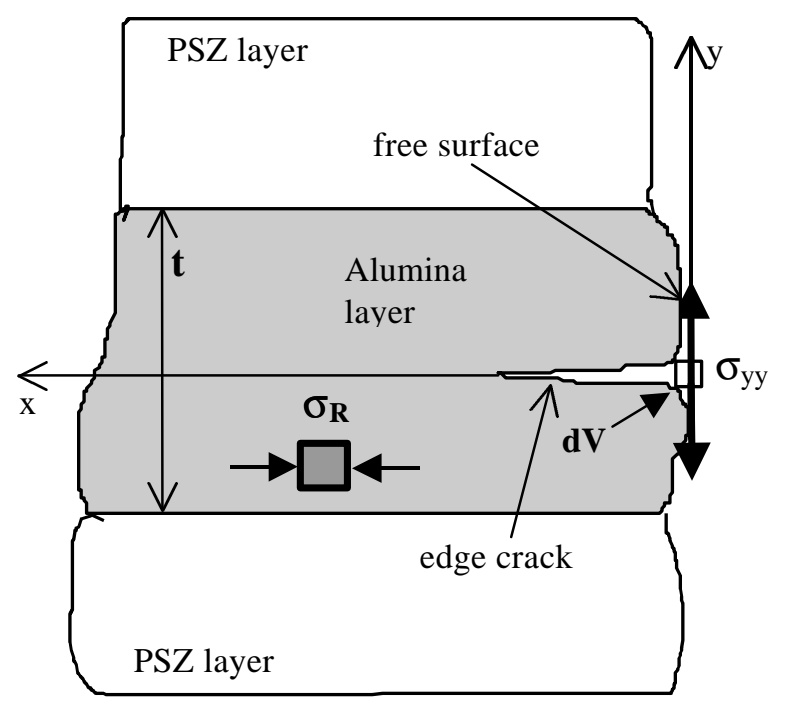

Figure 1. Tensile stresses at the free surface of a layer which is under residual bi-axial compressive stress far away from the surface. tion during the sintering of laminated composites are: (i) generation of stress due to the mismatch in the thermal expansion coefficients of the two adjacent layers or the thermal mismatch stress, and (ii) differential sintering rates of the two co-sintering layers which results from the difference in the sintering kinetics of the two powders. Hence to avoid the stress generation during processing, two modifications were made. For reducing the in-plane cracking, the individual layer thickness was reduced to $1 \mathrm{~mm}$. The effect of reduction of layer thickness on the inplane cracks or cracks parallel to the layer interfaces, has been discussed in detail afterwards. And the heating rate was also kept between $3^{\circ}-4^{\circ} \mathrm{C} / \mathrm{min}$ to reduce the generation of stress during the sintering of the powders due to their different sintering kinetics. In the initial sample (AZ2) the heating rate was not controlled and it was in the range $8^{\circ}-10^{\circ} \mathrm{C} / \mathrm{min}$. A lower heating rate results in slower sintering shrinkage of the two adjacent layers and hence a lower stress generation due to the lower shrinkage differential. After making these modifications, the second sample was hot pressed with 5 layers, each $1 \mathrm{~mm}$ thick (AZ1). But this sample had also extensive transverse as well as longitudinal cracking. To reduce the flaw generating stresses the laminate thickness was reduced further to $0.3 \mathrm{~mm}$. After reducing this target layer thickness, the third sample was hot pressed under the same conditions as earlier. In this sample (AZ03), the number of layers was increased to 9 to compensate for the lower layer thickness. It was comprised of 5 alumina and 4 PSZ layers. This sample came out as a single integrated compact without any major cracks. However, minor transverse cracks were noticed only in the PSZ layers.

From (1)-(3) explained earlier, the residual tensile stress in the PSZ layer was calculated for the AZ2 composite by using the material property values available from the standard literature (Shackelford 1992; Munro 1997). These property values are summarized in table 2 . It was found that in the AZ2 composite the residual tensile stress in the PSZ layer was $1350 \mathrm{MPa}$, which was higher than the tensile strength of PSZ and hence it was creating the transverse cracks in the layer. In the case of the AZ03 composite, the tensile stress in the PSZ layer was calculated

Table 2. Material property values of alumina and yttriapartially stabilized zirconia.

\begin{tabular}{lll}
\hline Property & Alumina & Y-PSZ \\
\hline Density $(\mathrm{g} / \mathrm{cc})$ & 3.97 & $6 \cdot 02$ \\
$\begin{array}{l}\text { Co-eff. of thermal } \\
\quad \text { expansion }\left(/{ }^{\circ} \mathrm{C}\right)\end{array}$ & $9.02 \times 10^{-6}$ & $12 \cdot 12 \times 10^{-6}$ \\
Young's modulus $(\mathrm{GPa})$ & 416 & \\
Poisson's ratio & 0.231 & 205 \\
Flexural strength $(\mathrm{MPa})$ & 355 & $0 \cdot 32$ \\
Tensile strength $(\mathrm{MPa})$ & 267 & 660 \\
\hline
\end{tabular}


to be $1125 \mathrm{MPa}$ which was still higher than the tensile strength of PSZ and thus responsible for creating the transverse cracks. In order to keep this tensile stress below the permissible limit, it was decided to replace the $100 \%$ PSZ and $100 \%$ alumina layers with a mixture of 15 vol.\% of each component into the other. This inter-mixing of the two components would reduce the difference in between the thermal expansion coefficients of the two layers and hence would result in an accompanied reduction in the thermal expansion mismatch. Before proceeding with this composition the residual tensile stress was calculated for the $\mathrm{ZA} 15$ (PSZ +15 vol. $\% \mathrm{Al}_{2} \mathrm{O}_{3}$ ) layer by using (1)-(3). The material properties of alumina and PSZ were properly modified by using the rule of mixtures. The tensile stress was calculated to be $760 \mathrm{MPa}$, which was considerably lower than that in the earlier cases (AZ2, AZ1 and AZ03). Thus 15 vol.\% of PSZ was mixed with alumina to replace the alumina layer and the PSZ layer was replaced by a mixture of 15 vol.\% alumina in PSZ. This composition is called AZ15 and a laminated composite was tried with this composition. The targeted layer thickness was $0.3 \mathrm{~mm}$ and the number of layers was 15 (8 layers of AZ15 and 7 layers of ZA15). This composite is designated as AZ1503. The composite AZ1503 was hot pressed under the same conditions as earlier. This composite came out as a single integrated compact without any cracks. Figure 2 a shows the as-cut cross sectional view of this composite. The white layers are the AZ15 layers and the dark grey layers are ZA15 layers. However, when this sample was cut on a high-speed diamond cutting machine for the examination of its cross-section, some minor transverse crack-like features were observed on the cut surface. These cracks were found to be present only in the Y-PSZ layers. They can be seen as small vertical white lines in the darker layers in figure $2 \mathrm{a}$. These crack-like features were believed to be a result of peeling up of small volume elements from those areas of the Y-PSZ layers, which were in contact with the diamond blade during cutting, because these layers are under a high residual tensile stress and also transmission of some amount of vibration from the cutting blade to the sample cannot be avoided while cutting it in the high-speed diamond cutting machine. To verify this assumption, radiography of the sample was carried out to detect the presence of any internal flaws or cracks. The radiograph, which is shown in figure $2 b$, did not show any internal cracks. Hence it was concluded that the sample was crackfree after processing. However, during the cutting opera-
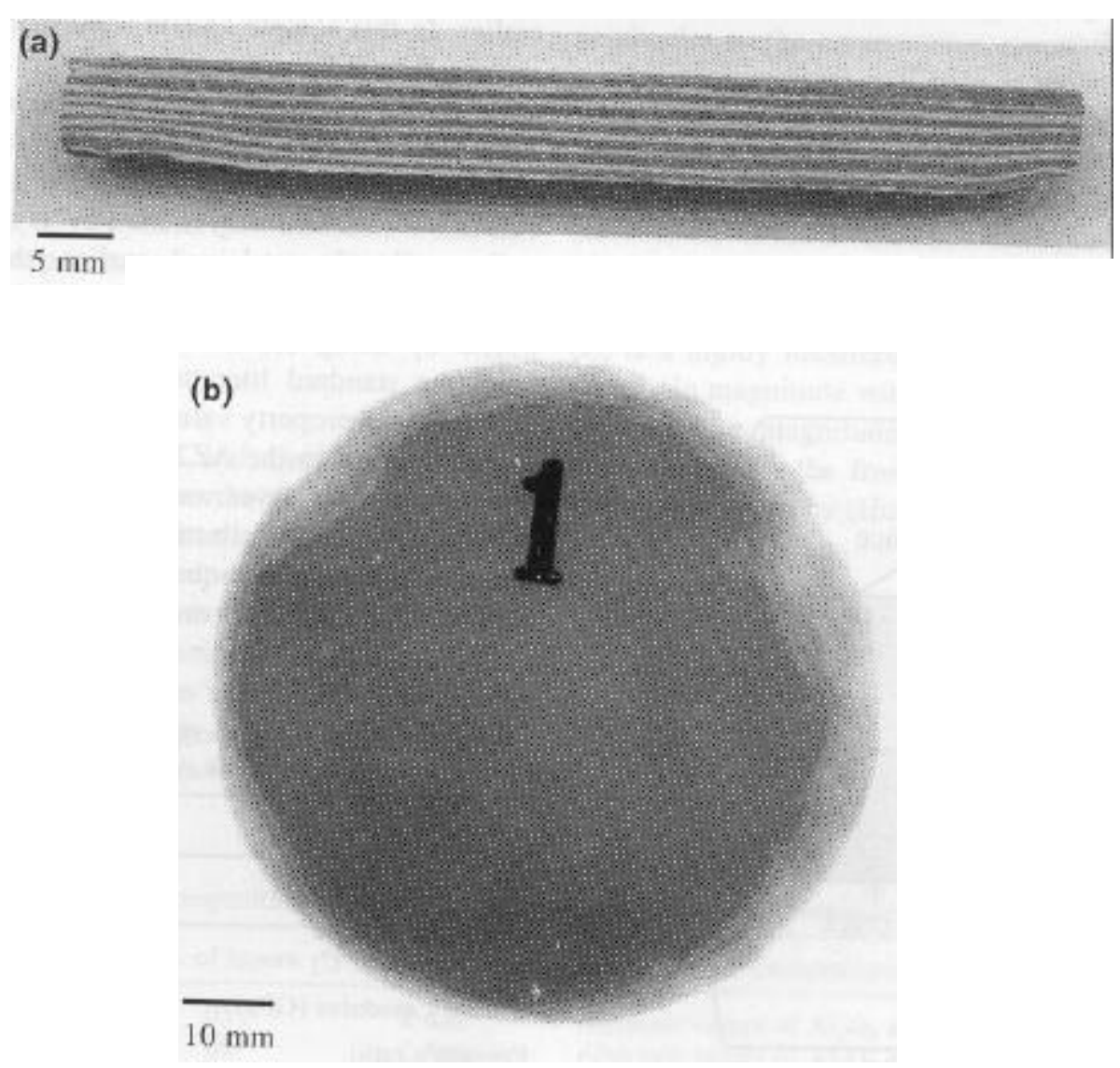

Figure 2. An as-cut cross section of the laminated composite with fifteen layers of alternate alumina (lighter) and Y-PSZ (darker) layers (a); and a radiograph of the as-hot pressed disc of the laminated composite showing the absence of any internal cracks (b). 
tion in the high-speed cutting machine, small portions of the Y-PSZ layers were getting chipped off due to the vibration from and of the blade as well as the high residual tensile stress in these layers.

After hot pressing of the laminates, principally two different kinds of defects or cracks were observed in them. One was channel or craze cracks, present only in the PSZ layers and the other type of crack was present in the alumina layers running parallel to the interface and creating delamination of the composite. The channel cracks in the PSZ layers are perpendicular to the interface and appear to be transverse cracks on any random crosssection of the composite. These cracks originated due to the thermal tensile residual stress (TRS). On a closer examination of the cracks in the PSZ layers, it was seen that there are two different kinds of transverse cracks. One set of cracks had a wider crack opening displacement (COD). The other type of cracks had a comparatively narrower crack opening displacement. Other than these two types of cracks some pore-like irregular shaped defects also could be seen in this layer. It is generally accepted that the cracks or defects with a wide COD are formed during the sintering stage due to differential shrinkage in between the layers. And the cracks with a small COD are formed due to the thermal mismatch stress during the cooling stage. All the above three types of defects are shown in figures 3 and 4 . In figure 3 the thick white layer at the centre of the photograph is a PSZ layer. In this PSZ layer two fine channel cracks (marked 1) at the right hand side along with a channel crack with wide COD (marked 2) and another irregular pore shaped pocket of alumina (marked 3) are visible. Similarly in figure 4 also a fine channel crack is visible partially at the extreme right and one more at the middle. At the left side of figure 4 a wide crack is present. The area indicated with a rectangle in

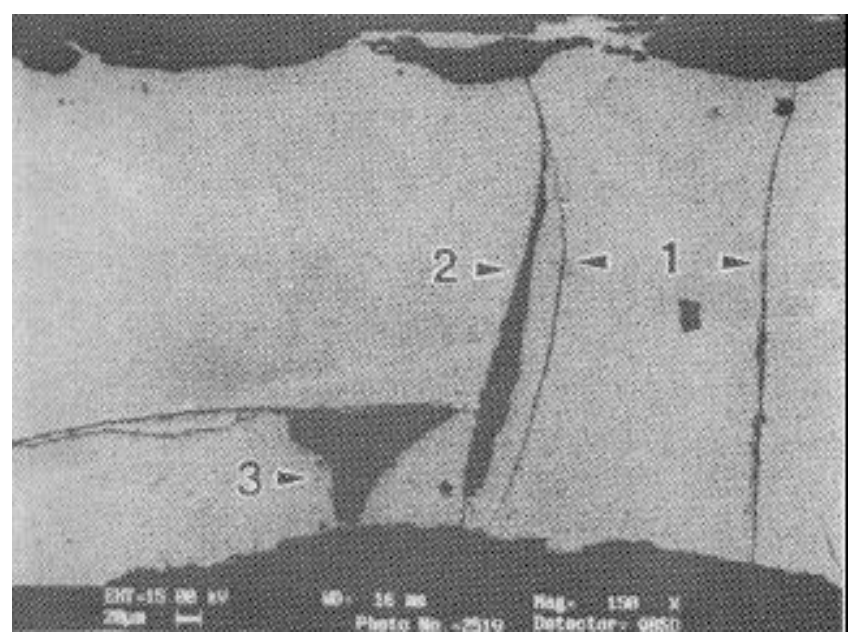

Figure 3. SEM image of PSZ layer showing the different types of defects in the layer i.e. fine channel or tunnel crack, wide channel crack, and irregular pore; marked 1, 2, and 3, respectively. figure 4 was examined at a higher magnification and is shown in figure 5 . This shows the cracked portion to be filled with alumina, which appears as the darker phase in back scattered electron image. This also supports the fact that this crack was formed during the sintering (heating up) stage when the powders started getting sintered. Due to the differential sintering rate and hence differential contraction of the two layers, this opening was formed in the PSZ layer, because sintering shrinkage of PSZ is more than that of alumina. The hot pressing direction is from the top of the layers, perpendicular to them. Due to this pressure, the alumina from the neighbouring layer flowed into the opening. Figure 5 also shows a fine thermal mismatch crack running along the interface of the alumina and PSZ. These thermal mismatch cracks have a welldefined, sharp edge, which is not present in the cracks

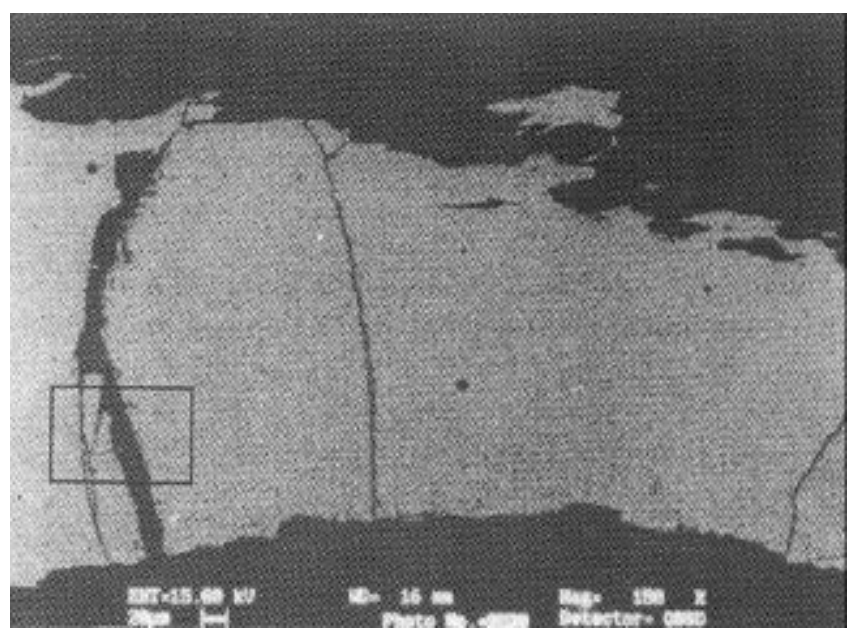

Figure 4. SEM image of a cross-section of a PSZ layer in a laminated composite showing the different types of cracks.

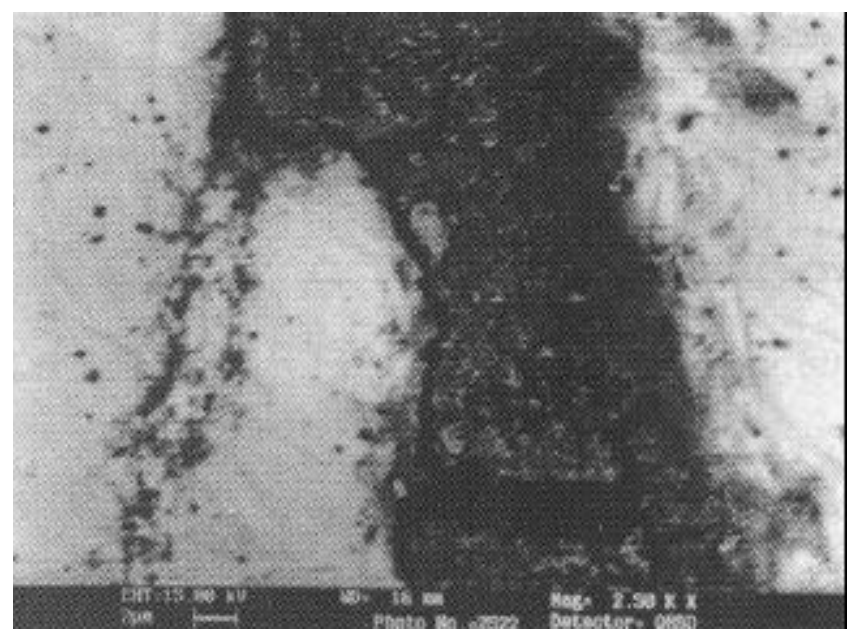

Figure 5. High magnification view of the area indicated with a rectangle in figure 4 showing a channel of alumina inside the PSZ layer and a thermal mismatch crack running along the left hand side interface. The white phase is PSZ and the black phase is alumina. 
caused due to sintering mismatch. The alumina pocket marked 3 in figure 3 might have been created during the process of powder laying inside the die.

The cracking of the alumina layers, which are under biaxial compressive TRS, may be explained in terms of

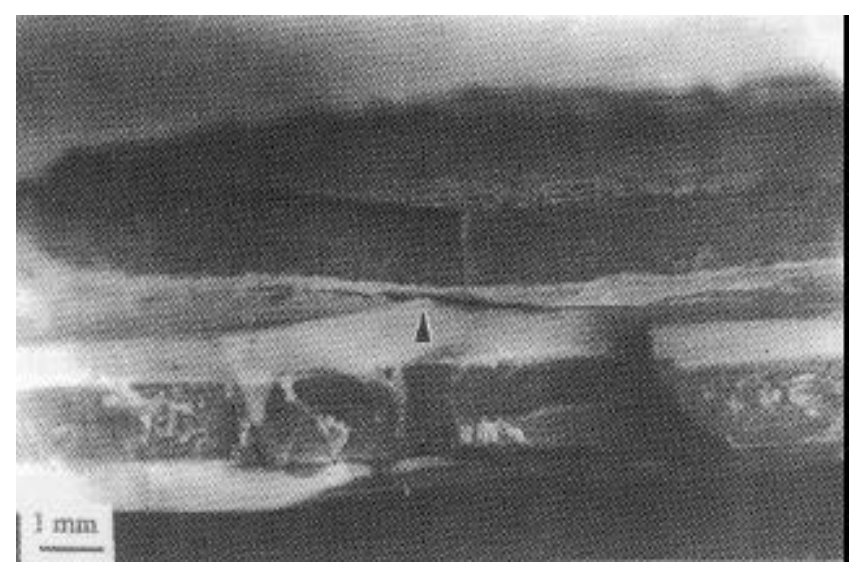

Figure 6. Stereo micrograph of a broken piece of laminated composite showing crack bifurcation phenomenon. A crack entering from the black PSZ layer into the white alumina layer bifurcates into two parts and deviates through a $90^{\circ}$ angle to propagate inside the alumina layer parallely to the layer interface.

(a)

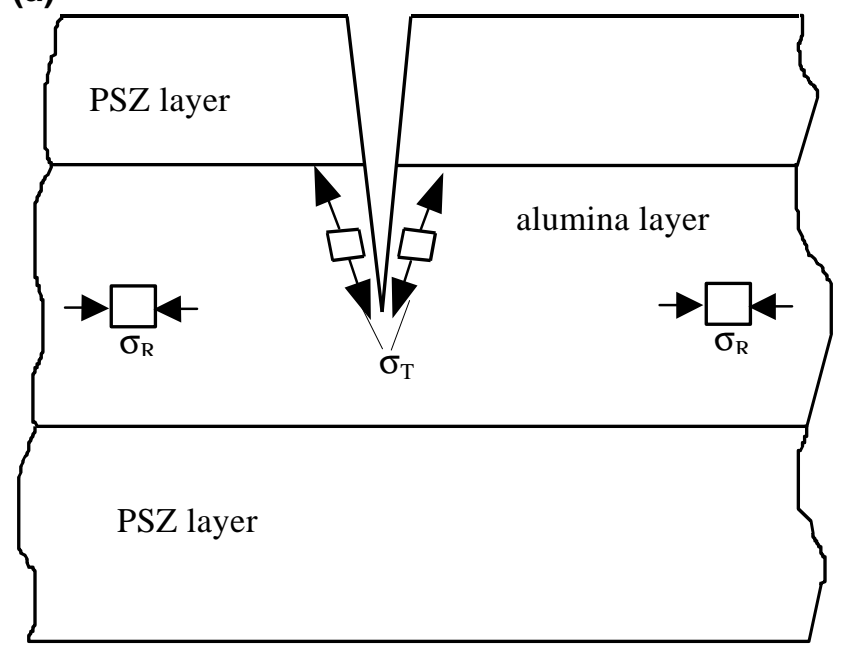

(b)

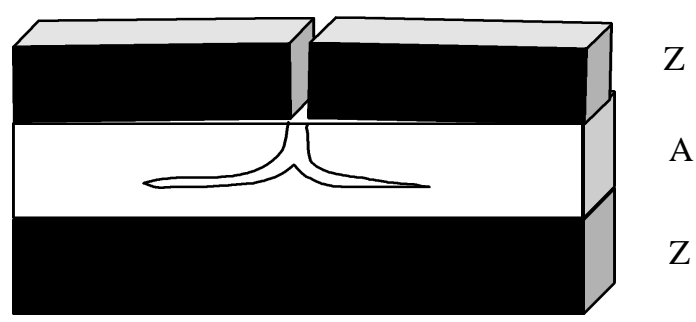

Figure 7. Schematic diagram of a propagating crack in a laminate under residual compressive stress (a), and schematic diagram of crack bifurcation in the compressive layer and the subsequent 'mountain ridge' formation (b). 'edge effect cracks' explained earlier. These cracks were all parallel to the interface thus indicating the presence of a tensile stress acting normally to the interface. A similar type of cracking in the alumina layers in alumina-PSZ layered composites have been reported by some other workers also (Ho et al 1995; Oeschner et al 1996; Cai et al 1997; Sergo et al 1997). The theoretical critical layer thickness for such cracks was calculated, as already explained, to be about $0.2 \mathrm{~mm}$. This value seems to be within reasonable limit of agreement with the experimental results. In our trials it was seen that in the initial composites, where the thickness of the alumina layers was in the range of $1 \mathrm{~mm}$ or more, this type of cracking was taking place. But once this thickness was reduced to about $0.3 \mathrm{~mm}$ these cracks did not occur. This suggests the experimental value of $t_{\mathrm{c}}$ to be about $0.3 \mathrm{~mm}$. The difference in the theoretical and experimental values of $t_{\mathrm{c}}$ can be due to the variation in the value of $\sigma_{R}$. Because $\sigma_{R}$ was only calculated theoretically from (1) and (2). The actual value of this residual stress was not measured. This residual stress measurement will be done in future during characterization of the composites. Another possible reason for the deviation in between the theoretical and experimental values of $t_{\mathrm{c}}$ is the non-uniform layer thickness of our composites. Since the powders were laid manually inside the die, it was not possible to maintain a uniform layer thickness throughout the cross-section of the composite. The non-uniformity in the layer thickness can be easily seen in figure $2 \mathrm{a}$. This non-uniform layer thickness might have given rise to a residual stress different from the theoretically calculated $\sigma_{\mathrm{R}}$.

This same 'edge-effect cracking' can also give rise to a new type of crack deflection process which has been called as 'crack bifurcation' (Oeschner et al 1996). This crack bifurcation could be seen with un-aided eye in the composites made during the early stages of our trials.

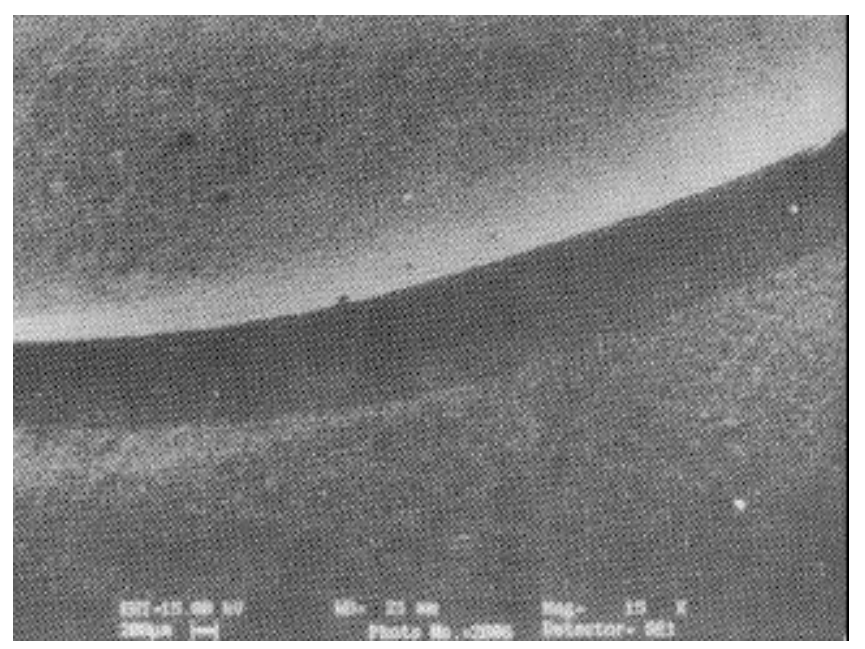

Figure 8. SEM image of the 'mountain ridge' in the alumina layer extending along the sample. This ridge is created where the crack takes a gradual $90^{\circ}$ turn inside the alumina layer. 
These composites were having a comparatively thicker alumina layer ( $1 \mathrm{~mm}$ and $2 \mathrm{~mm})$. Hence this thickness was more than the critical thickness $\left(t_{\mathrm{c}}\right)$ required for edgeeffect cracking as per (7) above. As seen in the stereo micrograph of figure 6 , a crack after passing through the black PSZ layer enters the white alumina layer. Upon entering the alumina layer this crack deflects at almost right angle and bifurcates into two separate cracks propagating sideways along the plane of the alumina layer. This crack bifurcation phenomenon can be explained with the help of the schematic diagram in figure $7 \mathrm{a}$. In this case we consider a crack propagating through the laminate as shown in figure $7 \mathrm{a}$. When a crack propagates through a laminate it creates a free surface. Thus when the crack enters the layer under residual compressive stress, $\sigma_{R}$, and creates a free surface, a situation similar to that at the edge of the layer is generated. This is similar to the situation discussed earlier. Under these circumstances a tensile stress, $\sigma_{\mathrm{T}}$, arise in the layer as shown in figure $7 \mathrm{a}$. This tensile stress may then cause the crack to bifurcate inside the compressive layer. As can be seen from the schematic diagram of figure $7 \mathrm{~b}$, the crack bifurcation phenomenon gives rise to a mountain ridge type of structure in the alumina layer at the point where the crack takes a gradual $90^{\circ}$ turn. A number of these ridges were clearly visible in many places on the alumina layers of the cracked samples of the initial stages. One such peak of the sample AZ1 was observed under SEM. The photographs are shown in figures $8-10$. Figure 8 shows a low magnification view of the mountain ridge type fracture from the top. The contrast is created due to the inclined nature of the two slopes on the two sides of the ridge. The peak is seen at a higher magnification in figure 9. This figure shows a slight difference in the nature of the fracture surface topography near the peak from that of the areas far away from the peak and lying on the plane surface. Though the fracture mode is essentially inter-granular in all the regions but near the peak some comparatively larger two-dimensional platelike grains are visible. These grains are shown in more closer view in figure 10 (marked with small arrows). After going down the slope to some extent the nature of the grains on the fracture surface becomes approximately uniform in all the three dimensions. As the crack enters the alumina layer from the top and a tensile stress builds up in the layer acting in a plane perpendicular to the layer, as explained earlier, the direction of the driving force for opening the crack changes. Once the crack bifurcates into two branches at the tip of the ridge (seen at the top right corner of figure 10) and starts deflecting gradually along the slope, the tensile force acting almost parallely to this surface (the surface of the 'mountain' near the tip) creates these plate shaped structures. Because at this region the tendency of the crack is to grow in a direction perpendicular to the surface. After the crack has taken almost a $90^{\circ}$ turn the tensile force acts perpendicular to the surface and the surface becomes usual equi-axial structured. Figure 11 shows such an area on the plain surface with equi-axial grains.

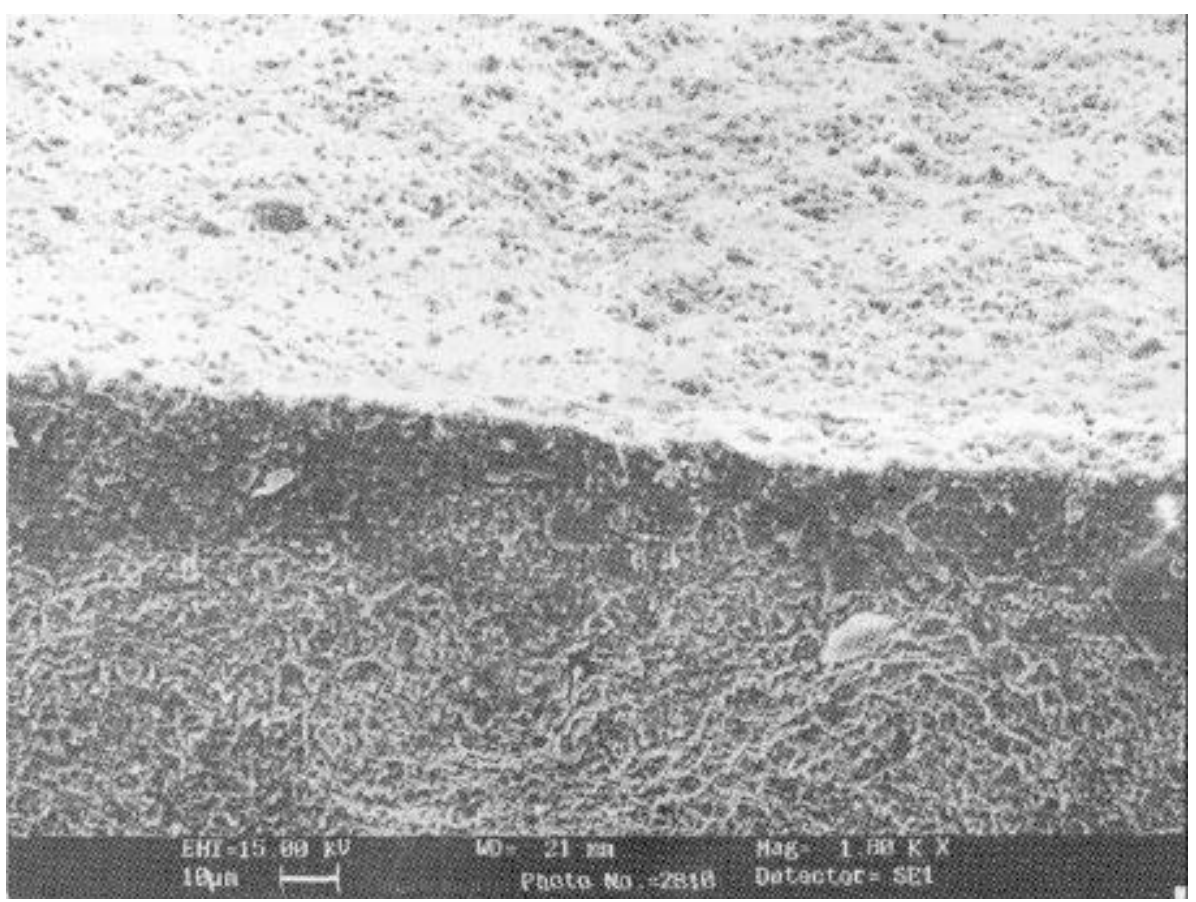

Figure 9. Closer view of the 'mountain' of figure 8 showing a slight variation in fracture surface topology between the area near the peak and areas lying well below the peak. 


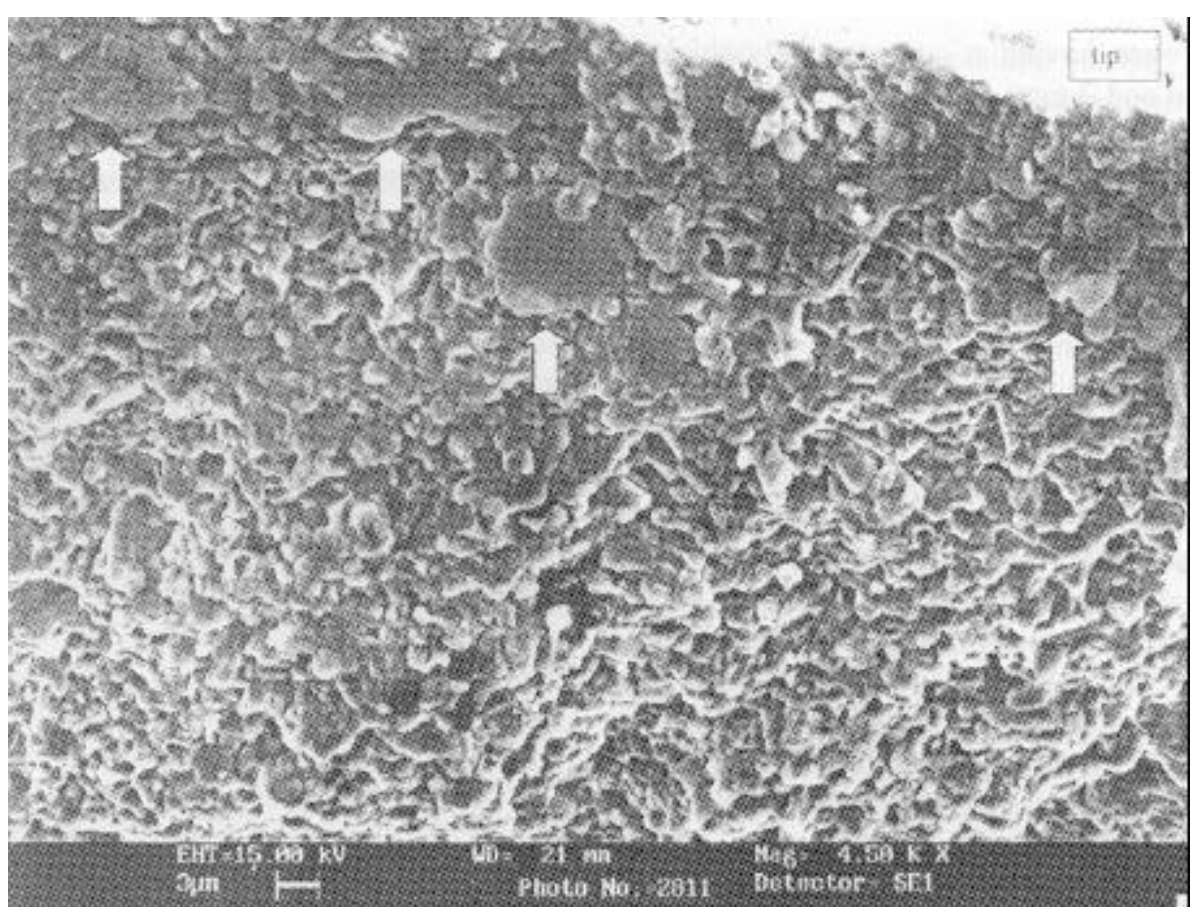

Figure 10. High magnification SEM image of the peak clearly showing the flaky structures (marked with arrows) near the peak. The peak can be seen at the top right corner of the photograph.

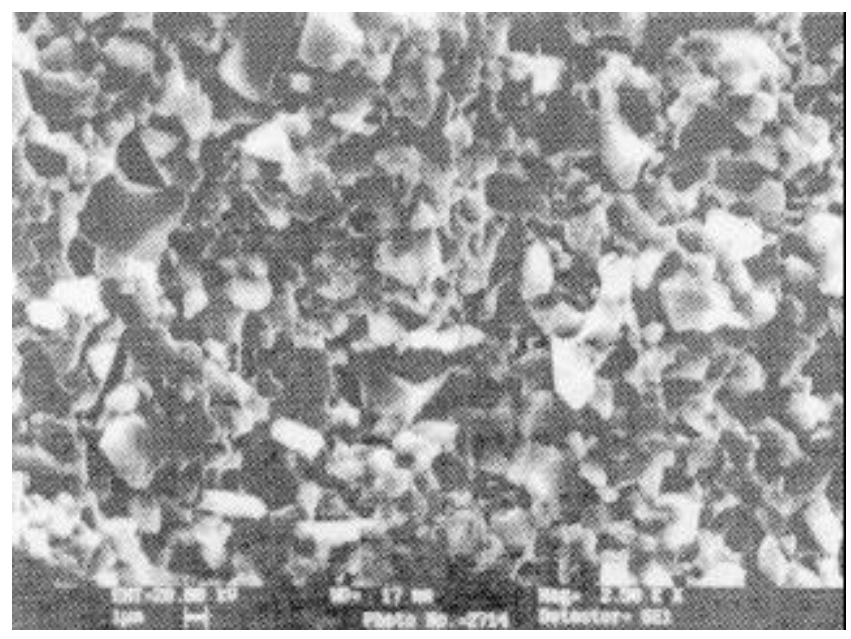

Figure 11. SEM image of the plane surface of the fractured alumina layer showing a typical equi-axial surface topology.

\section{Conclusions}

During the course of this optimization of the processing parameters for fabricating laminated ceramic composites different kinds of processing defects were encountered. A detailed study was made to understand the origins of these defects, mainly the channeling cracks and the edge effect cracks. The conclusions are as follows:

(I) The channeling cracks in the PSZ layers were found to be originating from the large difference in the thermal expansion coefficients of the two constituent layer materials and the resulting thermal expansion mismatch.

(II) The other type of cracks, the edge-effect cracks running parallel to the interface were being caused due to the residual tensile stress at the free edges of the alumina layer, which was otherwise under residual compression. This tensile stress acts in a direction perpendicular to the layer interfaces and opens up any pre-existing flaws or creates new cracks when their magnitude is sufficiently high. This tensile component of the residual stress reduces sharply with the distance from the free surface and is also strongly dependent on the thickness of the layer in which it acts.

To eliminate these two processing defects the following steps were taken: (i) to reduce the channel or transverse cracks in the PSZ layer, this layer was replaced by a mixture of $15 \mathrm{vol} . \%$ alumina with PSZ and the alumina layer was replaced by a composition of $15 \mathrm{vol} . \% \mathrm{PSZ}-85 \mathrm{vol} . \%$ alumina. This ensured a reduction in the difference in the thermal expansion coefficient of the two co-sintering layers and hence a reduced thermal mismatch strain. Also to reduce the sintering mismatch strain in between the two co-sintering layers the heating rate was kept low, in between $3^{\circ}-5^{\circ} \mathrm{C}$ per min and (ii) to avoid the edge effect cracking in the alumina layers this layer thickness was kept at around $0.3 \mathrm{~mm}$ so that the magnitude of the tensile stress component remains within tolerable limit.

By following the above two measures it was possible to successfully fabricate a laminated composite consisting of 
15 layers of about $0.3 \mathrm{~mm}$ thickness having 8 layers of alumina-15 vol.\% PSZ and 7 layers of PSZ-15 vol.\% alumina.

\section{Acknowledgements}

The authors would like to acknowledge the financial support from DRDO. We also thank Dr Roy Johnson, ARC International, Hyderabad, for his help in measuring CTE of the materials; and Mr M Srinivas Rao, for his active participation during the hot pressing of the samples. During the future course of this work the authors will also miss the presence of Late Mr M Hanumaiah, who had always been very helpful in doing the thankless job of polishing the samples through the long hours of day and night.

\section{References}

Amateau M F, Conway Jr J C and Bhagat Ram B 1993 Proceedings of the ninth international conference on composite materials (ICCM/9) (ed.) A Miravete (Madrid: University of Zaragoza, Woodhead Publishing Ltd.) Vol. II p 23

Cai P J, Green D J and Messing G L 1997 J. Am. Ceram. Soc. 801929

Clegg W J 1992 Acta Metall. Mater. 403085

Clegg W J, Kendall K, McN. Alford N, Button T W and Birchall J D 1990 Nature 347455

Ho S, Hillman C, Lange F F and Suo Z 1995 J. Am. Ceram. Soc. 782353

Munro R G 1997 J. Am. Ceram. Soc. 801919

Oeschner M, Hillman Craig and Lange F F 1996 J. Am. Ceram. Soc. 791834

Sergo V, Lipkin Don M, Portu G De and Clarke David R 1997 J. Am. Ceram. Soc. 801633

Shackelford James F (ed.) 1992 The CRC materials science and engineering handbook (Florida: CRC Press) p. 539 